\title{
Design of interactive and collaborative learning units using TICs in architectural construction education
}

\section{Diseño de unidades interactivas de aprendizaje colaborativo usando ICTs en la educación de construcción arquitectónica}

Núria Martí (Main Author)

Departamento de Arquitectura, La Salle Campus Barcelona, Universitat Ramon Llull

Sant Joan de la Salle 42, 08022, Barcelona (Spain)

nmarti@salle.url.edu

David Fonseca (Corresponding Author)

Departamento de Arquitectura, La Salle Campus Barcelona, Universitat Ramon Llull

Sant Joan de la Salle 42, 08022, Barcelona (Spain)

fonsi@salle.url.edu

\section{Enric Peña}

Departamento de Arquitectura, La Salle Campus Barcelona, Universitat Ramon Llull Sant Joan de la Salle 42, 08022, Barcelona (Spain)

enricp@salle.url.edu

\section{Marta Adroer}

Departamento de Arquitectura, La Salle Campus Barcelona, Universitat Ramon Llull Sant Joan de la Salle 42, 08022, Barcelona (Spain)

madroer@salle.url.edu

\section{David Simón}

Departamento de Arquitectura, La Salle Campus Barcelona, Universitat Ramon Llull Sant Joan de la Salle 42, 08022, Barcelona (Spain)

dsimon@salle.url.edu

Manuscript Code: 561

Date of Acceptance/Reception: 23.03.17/05.12.15

DOI: 10.7764/RDLC.16.1.33

\begin{abstract}
In the new context of the Information Society and online learning, offering architectural education based on interactive and collaborative methodologies can generate professionals capable of combining technical and aesthetic aptitudes. Adopting these teaching methods in the design and building construction courses can assist in enhancing student motivation. The programming steps of project-based learning using technological tools for research-knowledge and representation provide an additional educational dimension. This approach enables students to gain a much greater awareness of their own learning styles and goals, while also allowing them to recognize a conceptual relationship to, and ultimately a holistic view of, architecture. In this paper, the design of the course called Architectural Construction (to be thought in the second year of the architecture undergraduate course) is presented by describing different learning units offered through information technologies implementation (IT). The article draws attention to the new training paradigm, based on the implementation of IT as intrinsic mechanisms for the academic and professional future of the architecture framework.
\end{abstract}

Key words: Architecture, architectural construction learning, problem-based learning, representation, digital communication in construction.

\section{Resumen}

En el nuevo contexto de la Sociedad de la Información y el aprendizaje en línea, la enseñanza de la arquitectura basada en metodologías interactivas y colaborativas tiene la capacidad de habilitar profesionales capaces de combinar tecnología y aptitudes proyectuales. La adopción de nuevos métodos de enseñanza en el diseño y construcción de edificios mejoran la motivación de los estudiantes. La programación estratégica del aprendizaje basado en problemas utilizando herramientas tecnológicas permite profundizar en el conocimiento para la representación y la investigación de proyectos arquitectónicos. Este enfoque permite a los estudiantes adquirir una mayor conciencia de su estilo de aprendizaje y los objetivos del curso, estableciendo nuevas relaciones conceptuales y una visión holística de la arquitectura. En este artículo, se presenta el diseño del curso Construcción Arquitectónica II donde se describen las diferentes unidades de aprendizaje ofrecidas a través de las Tecnologías de la Información (TI). El artículo llama la atención sobre el nuevo paradigma de capacitación, basado en la aplicación de mecanismos intrínsecos para el curso académico y el futuro profesional del marco arquitectónico. 
The new era of Information Society (IS) has necessitated making changes to the way higher education is offered, as the focus has shifted to the acquisition of necessary skills, rather than theoretical knowledge. In the field of Engineering and Architecture (where we can also find additional studies, such as Construction Engineering or Civil Engineering), students and practitioners are required to possess both general and specific skills related to the use and control of the Information Technologies (IT). In architectural education, until recently, the use of IT was restricted to project implementation processes, where various applications such as Computer Assisted Design (CAD) served merely as aids in the execution of one's work. More recently, Building Information Modelling (BIM) applications have emerged, resulting in a significant leap in the parametric design of architectural projects.

However, the IT potential for teaching and learning extends beyond these tools, as it is increasingly being applied as a means of supporting educational practices and improving learning outcomes with the emphasis on understanding the content. The incorporation of the Technical Information and Communication Technologies (ICT) is essential to the new educational methods of the European Higher Education (EHEA). It promotes collaborative and cooperative learning, and motivates students to engage in self-learning aimed at ensuring that they acquire the skills necessary for success in their future careers (D. Fonseca, Redondo, Valls \& Villagrasa, 2016). In other words, this approach avoids passive "lectures" that are delivered by the teacher without any input from the students and do not benefit from the digital age and new IS. Nowadays, owing to the technologically "friendly" classes, students can benefit from new learning dynamics, many of which are based on content and online methods.

While such strategies are beneficial in all educational contexts, they are particularly relevant in architecture, and specifically in the construction sector, as the profession demands practical application of skills and knowledge gained, along with the contextual awareness. Hence, ICT is of great value in both educational and professional sector. In recognition of this fact, in this article, we propose a new approach to education in architecture. This new approach includes cross-learning, problem-based learning (Barkley, Major \& Cross, 2010) and strategically organized projects that allow students to acquire the highest quality of skills, ensuring that they can become successful autonomous learners (Monereo Font, 2012).

Description of the problem

Given that architecture is a discipline that blends theoretical and practical skills and knowledge and is characterized by a significant visual and spatial element, adoption of the new ICT tools in teaching and learning is very useful. Similarly, in the construction sector, the socio-economical and professional status of the practitioners has reached a critical point (it is necessary to use new tools without any previous education), and for these reasons the architecture learning has encountered an inflection. Thus, in order to move forward with times and benefit from new technological advances, the following factors must be addressed: (1) the socio-cultural crisis that has redefined the architectural space; (2) the economic crisis, which directly affects the construction sector; (3) significant and continuous advancements in the technological systems, which can become anachronistic if they strictly follow learning "guidelines"; and (4) the need to develop awareness regarding sustainability with respect to protecting the planet's limited resources, energy efficiency, and environmental cost of materials, among other aspects, which is becoming a key requirement in architectural project design and implementation.

Given these complex requirements, professional architects are facing the challenge of reevaluating the way the profession is perceived, prompting them to update the understanding of architecture. In the field of teaching, we believe that the challenge stems from the need to provide a more constructive and comprehensive education that would equip the newly qualified professionals with the skills needed to tackle any project in any situation, with a thoughtful, methodical and critical intellect. In this context, we propose a new approach to education in architecture that incorporates cross learning, PBL (Problem-Based Learning), collaborative learning, and strategic learning projects designed to allow students to acquire the most relevant skills through autonomous learning. These issues have been noted in "Teaching Innovation: Teaching and ICTs" (Ferro, Martínez \& Otero, 2009a) in which the strategically planned design of the subject is addressed. For these reasons, our work focuses on the acquisition of knowledge and skills by the student through collaborative tools and techniques that facilitate autonomous knowledge acquisition, and the migration of classic content to new digital platforms that allow access to information via interactive tools. 


\section{The Spanish architect and the competence skills}

In Spain, an architect is considered a professional capable of combining technical and aesthetic skills and using those abilities for the construction of buildings or urban planning. In this sense, an architect is both an "artist" and a "builder" with a complete view of architecture. Thus, the scope of the duties and responsibilities of an architect are in accordance with the provisions of European Directive 85/384 / EEC, the European Community, and the programs leading to the official qualification of an Architect. However, for these aims to be realized, architectural curriculum must maintain the proper balance between theory and practice and guarantee that, upon graduation, all students would possess the following specific aptitudes:

- The ability to develop architectural designs that satisfy both aesthetic and technical requirements

- An adequate knowledge of the history and theories of architecture and fine arts

- Suitable knowledge of urban design, planning and the skills involved in the planning process

- Capacity to understand the relationship between people and buildings

- Ability to understand the architectural profession and its role in society

- Knowledge of the methods of investigation and preparation of the construction project

- Awareness of structural design problems, as well as construction and civil engineering problems

- Adequate knowledge of physical problems and technologies, as well as the function of buildings

- Technical capacity to conceive buildings that meet user requirements

- Adequate knowledge of the industries, organizations, regulations and procedures involved in building projects integrating plans and planning

EHEA has transitioned from a model based on teaching focusing on the content towards a model based on acquisition of skills that will facilitate seamless integration into the workforce and allow the future professionals to respond to the rapidly changing market needs.

\section{Teaching and learning of Architectural Construction in the Information Society}

Adoption of the new systems of teaching and learning that focus on the acquisition of skills has changed the roles of students and teachers, as the emphasis is no longer on passive knowledge transfer, but rather on interaction, the space-time coordinates and access to resources, which requires modification of all existing instructional methodologies. These new systems are not just tools that can enhance and facilitate the traditional teaching, but rather methods that can improve skill acquisition in new ways. The strategy of combining significant learning methodologies (reception and discovery) with PBL makes the relationships among the elements of the interactive didactic triangle (teacher, student and content) and the participation of ICT more active and valued. The model is based on the current teaching context characterized by a high degree of complexity and great dynamism, necessitating the integration of multiple knowledge components, namely the curriculum, the pedagogy and the technical component.

Therefore, to achieve optimal learning outcomes, it is necessary to know the profiles of all students, as well as understand the role of the professor. Modern students are often referred to as Digital Natives (Prensky, 2004), in reference to their reliance on online social media for communication and access to information, as most are conducting their lives in the virtual environments (which are appropriately dubbed "e-lives"). Therefore, just as cyberspace is a constituent part of students' everyday life, ICT tools are part of their modus vivendi, and the digital network is: How they communicate, meet, interact and socialize with others; the way they search, create, share, exchange and collect information; and the means, by which they cooperate, learn and evaluate their achievements, analyze problems and publicize their ideas and conclusions. In recognition of this paradigm shift in the way new generations are living their lives and interacting with the world around them, "Collaborative Educational Design" is widely recognized as a necessary component of teaching and learning in all educational contexts (Glick, Clevenger \& Porter, 2011a; Kocaturk, 2010; Kondratova \& Goldfarb, 2004). As the focus of the present investigation is on teaching of subjects related to Construction, we believe that those who have contributed new approaches, especially in the acquisition and improvement of spatial abilities of the student, can inform us on the best use of ICT in the educational context.

In architectural design, the space is represented using traditional methods, such as printed plans and models (work from $2 \mathrm{D}$ to $3 \mathrm{D}$ ), as well as current methods, such as digital maps and 3D models, which facilitate appreciating a 
greater level of detail (David Fonseca, Martí, Redondo, Navarro \& Sánchez, 2014). These advanced visualization methods allow both students and practitioners to work collaboratively and communicate their ideas. Most importantly, they facilitate more efficient management of the overall project space (Bouchlaghem, Shang, Whyte \& Ganah, 2005; Leopold, Gorska \& Sorby, 2001a). The use of certain collaborative ICTs permits the design, development and implementation of functional, sustainable and intelligent projects, which is also referred to as Intelligent DesignBased Learning - IDBL (Nawari, 2010).

\section{Teacher's role and the skills to acquire}

Owing to the shift in educational focus from knowledge to skill acquisition, the role of the teacher has changed significantly, as the traditional learning model tends to focus on the curriculum content, rather than its practical application. However, in the digital era, the teacher is no longer a mere transmitter of information and the central protagonist of exchanges among students (Fonseca, Climent, Vicent \& Canaleta, 2016). Rather, the teacher has become a manager of the available resources, a tutor and a consultant in resolving doubts, a counselor and a guide in conducting projects, and a mediator in debates and discussions.

In the specific case of the "Construction" course, the teacher is an active professional architect who has direct experience of the discipline and a holistic approach to architecture. Therefore, he/she recognizes the need to convey both the curriculum content and the work experience on site during the lectures. The emphasis of this holistic approach to learning is on gaining skills that can be transferred to the professional practice. In the academic portfolio, the acquisition of specific skills is divided into three courses. These basic concepts and requirements will be used later on in higher-level courses and will be applied in Executive Projects. To achieve these objectives, the faculty must master the following skills: (1) search and select information; (2) understand the essence of the information, infer their consequences and conclusions; (3) read different languages (English) and multimedia systems; (4) use various information databases; and (5) manage, store and present information organized according to different purposes.

Considering that computers and other personal technology, such as Smartphones, have become ubiquitous communication devices to the extent of becoming invisible to our everyday landscape as an element thereof (Weiser, 1991a), learning the proper management of ICT and ubiquitous learning is imperative. Against this backdrop, the capacity for analysis and synthesis, teamwork, environmental sensitivity and ability to apply knowledge to practice are among the key general competencies that each student must develop.

Methodology: Teaching Construction-II

The following sections describe in detail the design and methodology of the Construction II undergraduate curriculum, for which a model of active learning based on various strategically interrelated units, is proposed, with the platform eStudy ICT collaborative tools at its core. The subject of the first course pertains to two thematic areas: matter and order (building materials, the demands of support and comfort and organizational forms needed to meet these demands). In the second academic year, the course scope extends to in-depth examination of the systems of heavy / wet construction support and building comfort. Finally, in Construction III, the focus is on the dry construction system support, comfort of buildings and interior systems, and support systems of the fuzzy knowledge structures. In the present case, the learning of these units consists of Project's Program Based Learning (P's PBL); research seminars related to learning activities; days dedicated to "in situ technology"; teaching materials eStudy (the Mooddle platform of the school), tutorials and laboratory visits.

\section{Project's PBL}

Barrows (1999) defined PBL as a student-centered pedagogy allowing students to learn about a subject through problem solving. Therefore, PBL is an instructional (and curricular) learner-centered approach that empowers learners to conduct research, integrate theory and practice, and apply knowledge and skills to develop a viable solution to a defined problem. The PBL, in the context of contemporary architecture, is based on the realization of a professional executive project of a well-known architect's building of the mid-twentieth century. As a part of the project, students are required to apply current technical regulations when reinterpreting the existing solution, while retaining the aesthetics and composition of the constructed building. Dealing with a complex problem, it is common to identify the problems that must be solved and divide them into blocks, according to Table 1. 


\begin{tabular}{|c|c|c|c|}
\hline \multicolumn{3}{|c|}{ StageStepsObjective } & \multirow{2}{*}{$\begin{array}{l}\text { Strategy } \\
\text { First statement of the case and problem analysis }\end{array}$} \\
\hline A & - & Introduction to PBL complex & \\
\hline B & - & $\begin{array}{l}\text { Divide the problem into } \\
\text { blocks }\end{array}$ & $\begin{array}{l}\text { Identify areas of knowledge, explain, analyze and understand the } \\
\text { requirements }\end{array}$ \\
\hline \multirow{6}{*}{$\begin{array}{l}\times \\
\stackrel{x}{+} \\
\stackrel{\sim}{u}\end{array}$} & 1 & Increase in information & $\begin{array}{l}\text { Provide a more accurate approximation to the reality behind the } \\
\text { problem. Explore all possible solutions }\end{array}$ \\
\hline & 2 & $\begin{array}{l}\text { Hypothetic work based on } \\
\text { systems }\end{array}$ & $\begin{array}{l}\text { Apply knowledge to the hypothesis pertaining to construction systems. } \\
\text { Detect problems and advantages }\end{array}$ \\
\hline & 3 & $\begin{array}{l}\text { Selection of proposals to be } \\
\text { developed }\end{array}$ & Review the hypotheses based on the requirements \\
\hline & 4 & $\begin{array}{l}\text { Analyze "pitfalls" of the } \\
\text { hypothesis }\end{array}$ & $\begin{array}{l}\text { Locate the singularities of the system. Work on solutions. Revise plans } \\
\text { based on the requirements }\end{array}$ \\
\hline & 5 & $\begin{array}{l}\text { Formulate the proposed } \\
\text { solution }\end{array}$ & $\begin{array}{l}\text { Change / reaffirm the concreteness of the problem based on STEP } 3 \\
\text { Provide } 41 / 100 \text { scale solution }\end{array}$ \\
\hline & 6 & Revision PBL1 & Check consistency with the project and requirements \\
\hline $\mathrm{D}$ & - & Propose solution & Results presentation \\
\hline $\mathrm{E}$ & - & Evaluation & Qualitative revision \\
\hline
\end{tabular}

In phase $A$, the building that is going to be worked on is presented, introducing the context, with respect to the leading architect and his/her architecture, analyzing to project by observing the building and searching the information of the location.

In Phase B, students are required to engage in discussions, the aim of which is to establish the level of knowledge they possess and motivate them to reflect on the complex problems associated with the project execution. In this phase, the goal is to ensure that the students understand the scope of the problem and can address it in an orderly and themed way, as this allows them to define clear guidelines to follow. This process results in a clear conceptual map the students can use to understand and address the problem. In these early stages, both in the classroom and at home, the students must seek information repositories pertaining to the disciplines involved in solving the problem.

Phase $\mathrm{C}$ is the core of PBL. The students have to analyze, investigate and synthesize documents, as well as critically reflect on the information obtained. They accomplish this by trial and error, which is necessary for reaching the most appropriate solution. In this approach, the teacher has full control of every problem and sets the time required for solving each one. However, the teacher does not have the final solution, but rather researches possible solutions with students, thus advancing knowledge and understanding of the pertinent subject area. Another advantage of this approach is in identifying different ways to identify problems and research. These guidelines lead to developed work and are associated with several objectives. The teacher relies on predesigned strategies and certain working tools to facilitate the approach to the objectives.

In the sequence of blocks, as well as in the sequence of steps within each block, the change of scale is needed to obtain the final proposals that address the complexity of the architectural problem without simplifications or inaccuracies. Figure 1 shows how the aforementioned process was implemented in the classroom, whereby students first developed a proposal by hand-drawing the solutions on paper, which helped them with identifying the difficulties and advantages of the first approach. To assess the hypothesis defined based on the requirements, a real model was created, allowing the students to verify the correctness of the requirements proposed. Finally, the students worked on detailed drawings in 2D, and displayed their designs in 1/200 scale using 3D singular points.

Once the solution is defined, the students must specify the construction details, including any changes to the problem specification, and reaffirming the resolution scale 1:50-20; 1:10-5. The specific requirements are tabulated in detail and each one is reviewed to verify that all the premises are correct. This last step is performed in each block of subproblems, and is intended to be reviewed and modified if necessary in order to ensure alignment with the proposed solution for the particular block, as well as the consistency with the complex view of the problem as a whole (Figure 2). In this instruction, the faculty is a cognitive mediator because the students are neither given a unique solution nor 
a unique way of thinking. Instead, they take charge of their own learning and are encouraged to self-regulate, which helps them understand that learning is a social phenomenon that requires individuals to be receptive to the ideas of others, to be open to proposals and reconcile conflicting or opposing arguments (Barkley et al., 2010).
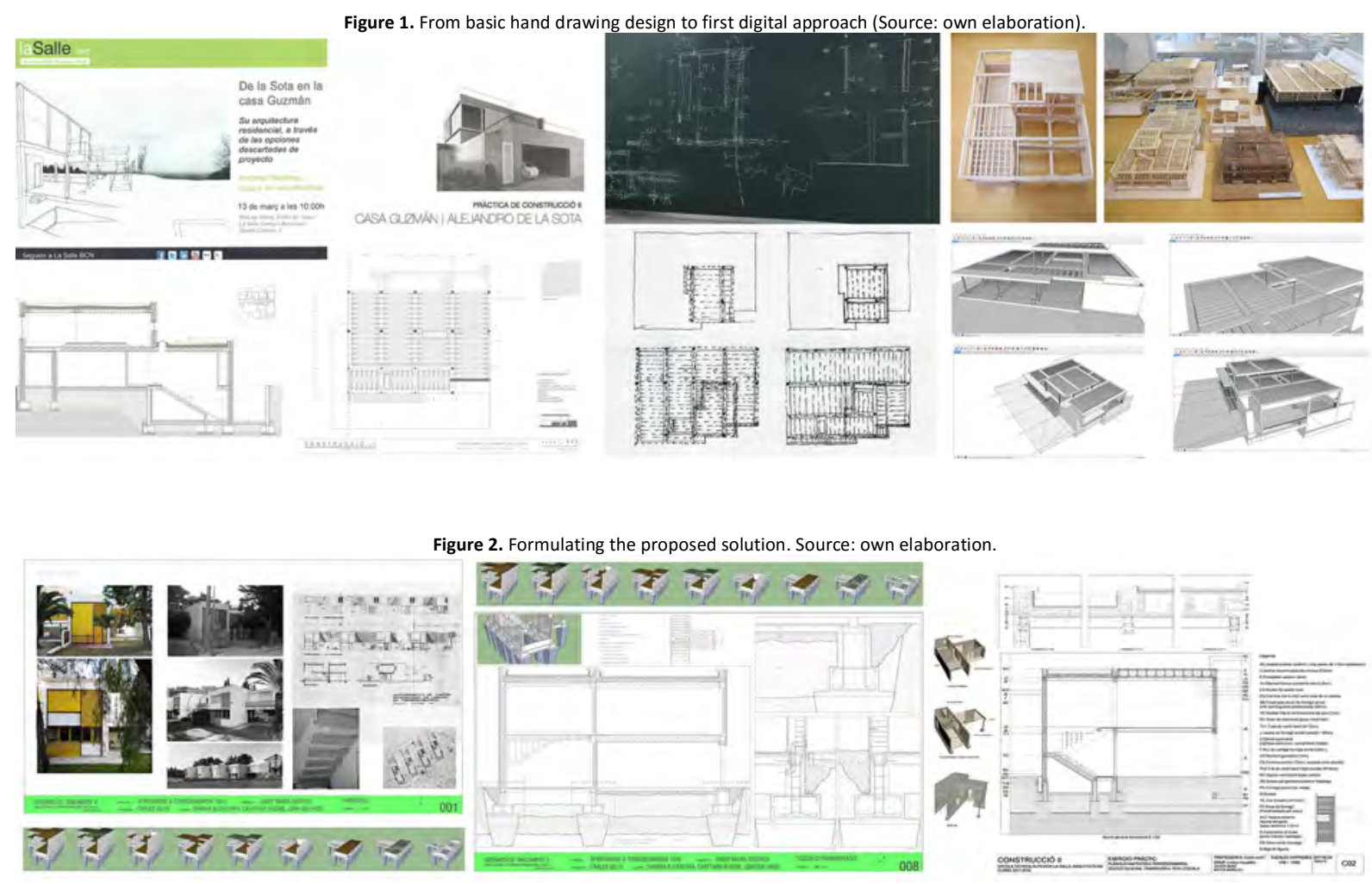

Results: Using Seminar for Auto-Assessment

The proposed program is based on active training seminars, as a part of which the students participate in the development of their own knowledge and improve the quality of their work by applying different learning techniques. The structure of these seminars is based on participatory lectures, "Pills" (exhibition of images), and practical tasks, as this allows several themes to be explored in each session (Marchesi, 2004a). The main advantage of these sessions is their participatory nature, which is ensured by instructing students to prepare for the seminar by consulting the notes on the subject using the eStudy platform, allowing them to address any doubts or questions to the teachers and they self. The "pill images" sessions introduce an abstract concept into a concrete situation, allowing the students to contextualize and understand it better. The images pertain to the site projects that the faculty members are working on, and may include both photographs and videos of implementation processes pertaining to different building systems.

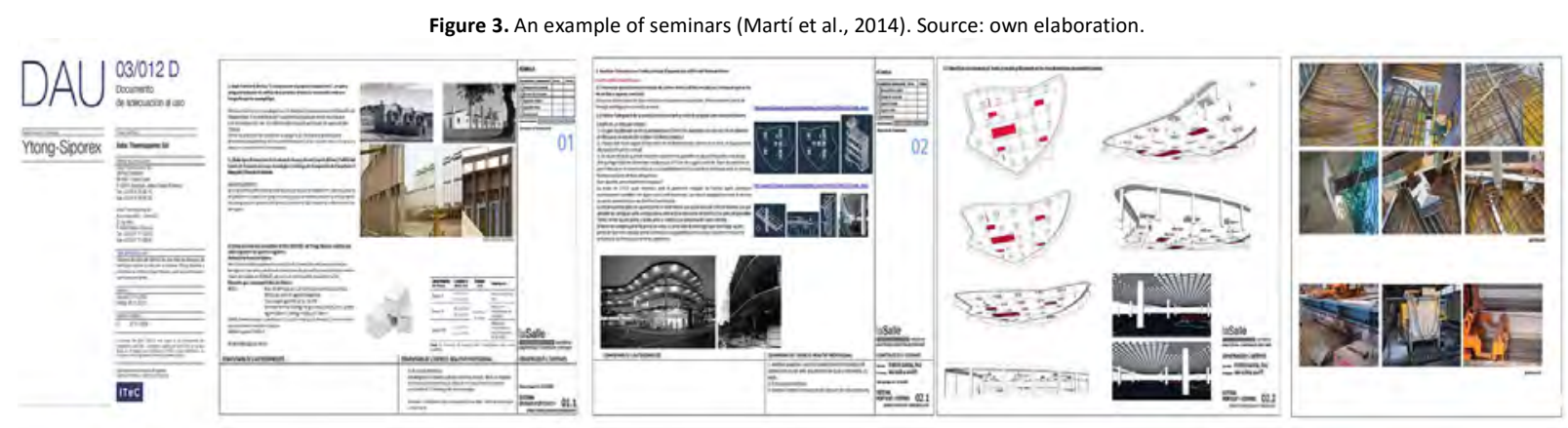




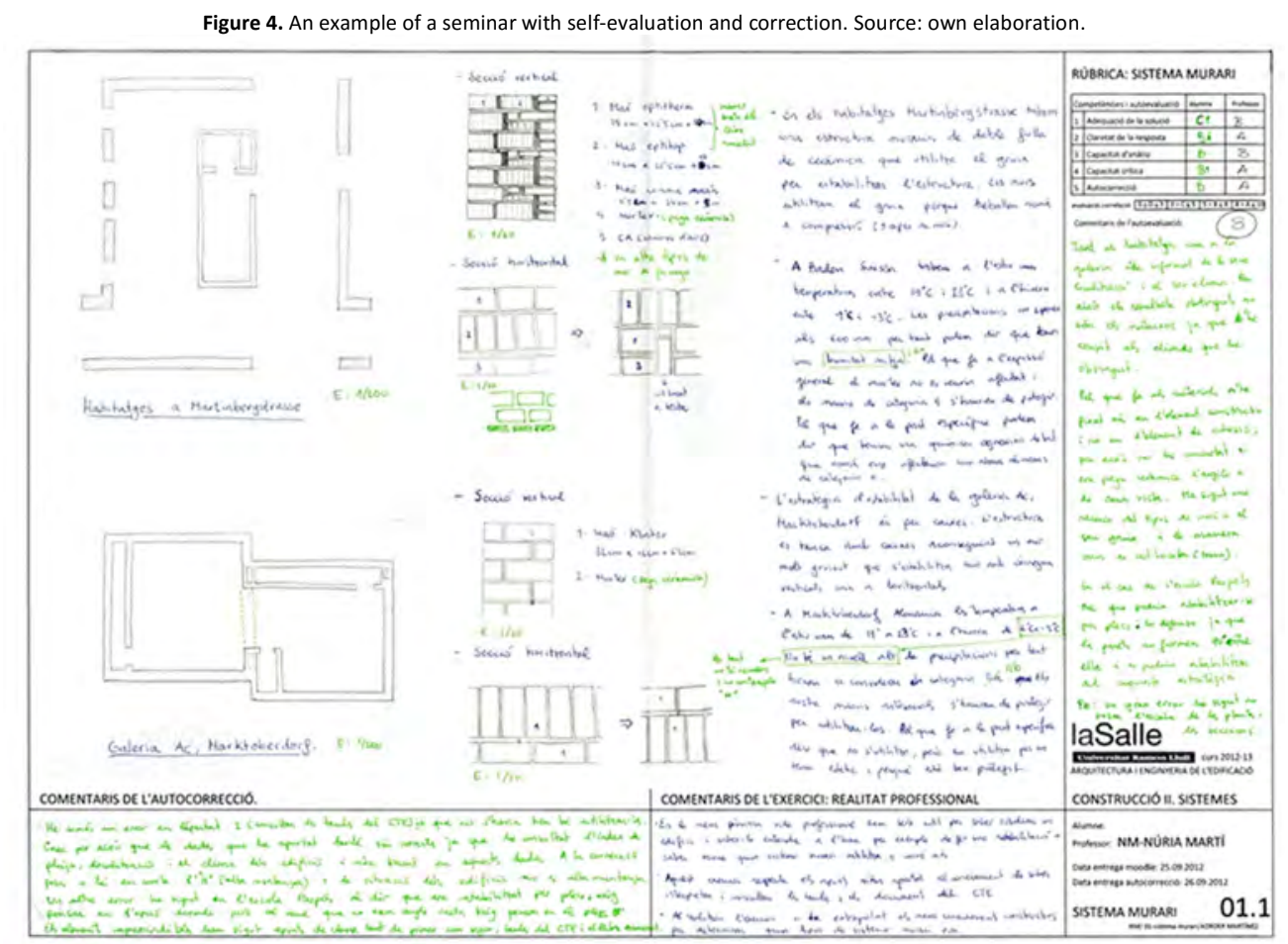

The first objective of the task is achieved by encouraging the students to assimilate, manage and expand the knowledge imparted. The second objective arises in the research of various exercises, such as: researching a topic and the technical expertise associated with it, establishing a relation between textual information and a constructive detail, having a detailed 2D representation of a 3D model structure, and organizing concepts as theoretical sessions. The third objective is achieved through self-correction exercises, comments on the exercises and their projection in the professional world. Three concepts are self-assessed as a part of this activity: (1) the success of the solution, (2) understanding of the academic content of the current course, and (3) the transferable skills, such as analytical and critical thinking. To implement this system, the tasks must follow a predefined format and are executed in three steps:

- Perform the exercise; provide the comments and self-reflection using a PDF file (Figure 3).

- Once the deadline is closed, the faculty provides the solution on the platform, and the students can self-correct any errors in their work

- Finally, the students are asked to complete the rubric (Figure 4), that is a self-evaluation table.

The proposed strategy incorporates training activities focused on practical and theoretical approaches. Each day of the seminar incorporates execution, roundtables and practical tasks. The first stage is entirely practical, and consists of setting up various building systems to run full (1:1) scale (Figure 5). At this time, the students create sketches, make note of details, and take pictures and videos.

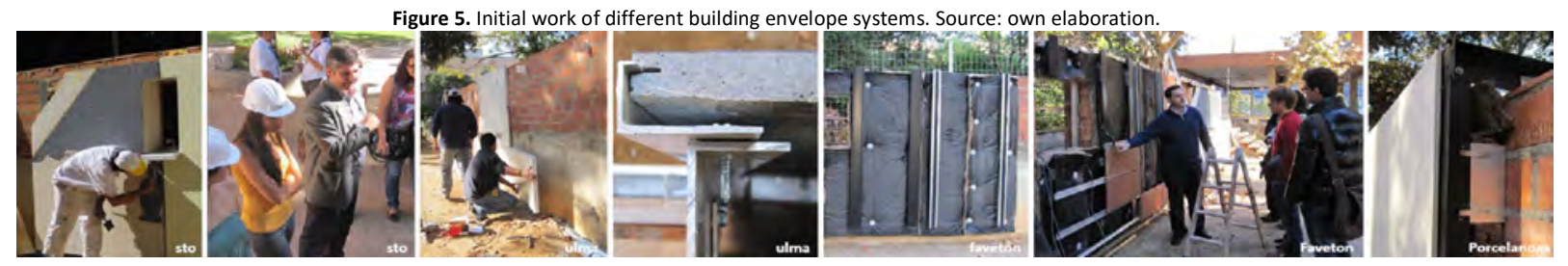

The second stage is both theoretical and practical, as it involves conferences and roundtables, where the various building systems are discussed with industry professionals, architects and teachers. Therefore, this constructive discussion aids in the students' understanding of the course content, allowing them to appreciate the existence of more than one possible solution to the same problem. 
The final stage involves individual practical work that interrelates "in situ technology" discussed with the theoretical knowledge covered in the seminars. It is executed in presentation format, whereby the students use photos, 2D and 3D drawings, as well as text and tables that justify and contrast the theoretical concepts objectively, to convey what they have learned in the preceding period. These presentations can also serve as students' notes, as they provide chronological record of the work they have done. They also learn how to structure information hierarchically according to the relevance of theoretical concepts.

The students also benefit from a blog, which they can use to interact with their peers and where teachers announce various activities taking place in the professional field related to the area of study. This informal platform allows students to test the efficacy of the notes in order to have an effective delivery. For a more dynamic reading and more active learning, students can augment the notes with various interactive applications, such as an image gallery attached to texts, videos and presentations and documentaries with attributes. In addition, note-based practice exercises and review tests with live and screencast solutions are incorporated at the end of the theoretical part, assisting in more engaged autonomous learning. In order to ascertain the students' use of technology and their IT proficiency, a pilot survey was conducted, revealing that $35 \%$ of the students use Mac, $41 \%$ rely on an iPhone while $14 \%$ own an iPad (David Fonseca et al., 2014). In addition, the remaining $20 \%$ of the students that do not possess any of these devices plan to acquire at least one in the near future, confirming that the continued use of the method is valid (using interactive ibooks). For students who do not have Mac devices, notes are provided in PDF format and they can also access active genes pictures through QRmovie.

Figure 6. Design of strategic proposal. Source: own elaboration.

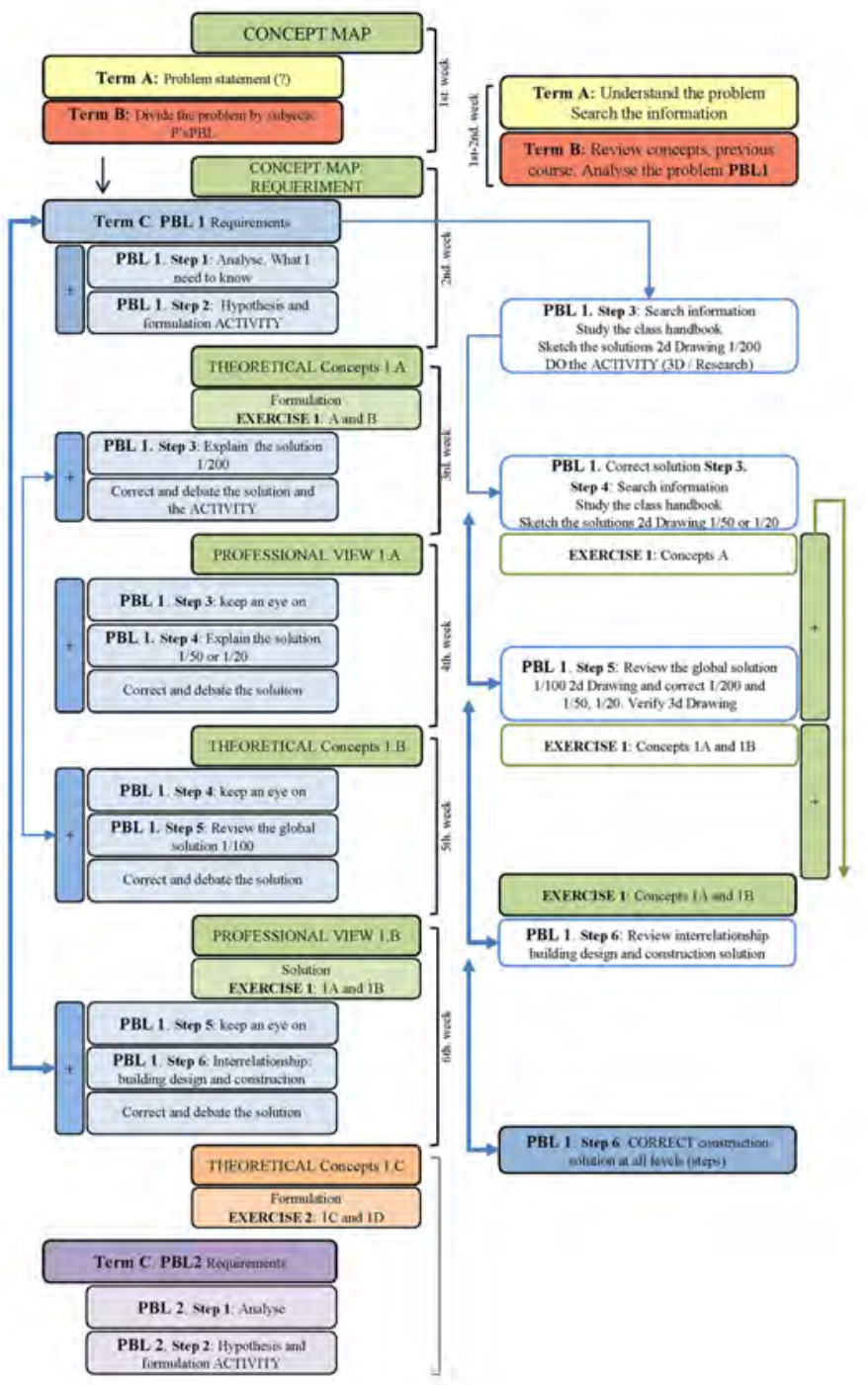


At the time of addressing the problems in P's PBL, theoretical themes relating to each have not yet been taught in class. In other words, the students have not been provided with the theoretical knowledge required for tackling the problem proposed, although there are notes and sources they can consult. As a result, in the Step 1 Block B, the students must consider the problem from the "what I know" perspective. In this first stage of Step 1, the teacher would take the initiative in the classroom by providing the first approach to the problem, thus narrowing down the range of the potential paths. In addition, he/she directs the various solutions through leading a question-based discussion. The teacher reveals different patterns associated with the problem. From this moment on, the students must continue asking questions, aiming to gain in-depth understanding of the reality behind the problem. This gap between the two learning units makes students more independent and self-critical, and prompts them to work more actively. It also assists with self-regulating their knowledge and taking the responsibility for the acquisition of skills.

In the strategic design described here (Figure 6), seminars are more closely related to concrete elements that, by moving to P's PBL, provide tools that can be used for analysis, research, representation and communication. All the instructions, when combined into a coherent unit, allow the students to attain a holistic view of construction as an architectural discipline, which involves many factors and requirements that are addressed depending on different design solutions.

\section{Conclusions and Discussion}

Learning through acquiring competencies is an intrinsic educational model that has become necessary for the advancement of architectural education and its alignment with the changes in the industry as well as in the society as a whole. Education offered to architecture students should integrate professional skills, abilities and knowledge and allow the graduates to apply them to the design and construction of buildings. In other words, a professional should be able to:

- Elaborate architectural designs that satisfy both aesthetic and technical requirements, from a holistic view of all the disciplines of architecture.

- Adapt to new circumstances by utilizing the acquired knowledge and the capacities and skills.

- Continue to acquire new knowledge and skills, keep informed of new materials, technology systems, policies and behavior of the constructed buildings, as well as extend the curriculum area to incorporate appreciation of new cultural developments, and the latest ICT tools.

- Use different resources for researching, knowledge acquisition, representation and communication.

The incorporation of ICT in learning opens up new psycho-pedagogical dimensions when considered not only as instrumental, but also as an instructional and techno-pedagogical tool. The blurring of boundaries involves working within a framework of information and virtual communication. In architecture, this approach necessitates the use of digital library tools, both graphic and written. The optimization of resources and agility in the execution of an architectural project requires use of software that allows links across various disciplines to be forged and utilized. The incorporation of ICT in educational practice allows:

- Opening new architectural conceptual dimensions.

- Intensifying work using computer programs to create documents and virtual environments for communication and information storage/sharing (Grife, Carcaño \& Fajardo, 2014).

- Facilitating the acquisition of both generic and specific skills.

- Allowing students to focus on meta-reflection and metacognition of their own learning, with a particular focus on new fields in the construction process, such as environmental studies (C Torres-Machi, Yepes, Chamorro \& Pellicer, 2014).

- Monitoring the students' learning.

In conclusion, we can affirm that the learning outcomes were very favorable. According to an anonymous survey, its performance exceeds the average of 6/10. Regarding student learning, the program has resulted in remarkable improvements in both theoretical knowledge acquisition and ability to analyze situations and detect some of the problems to be solved, from their construction skills and behavior of materials.

However, the dedication, effort and concentration needed to succeed in this program are much higher than those demanded of the students taking part in traditional instruction. Thus, the empathy and collaboration between students and teachers is crucial. According to the assessment of the faculty, the initiative has received a very positive rating of $4 / 5$, in terms of knowledge acquisition, care and clarity of explanation. It is very important for the success of this format to provide a precise set of goals, both in "the amount of knowledge to impart," and in all activities that are 
generated in the process. P's PBL design is closely aligned with the complexity of the architectural reality. For this reason, segmenting the project into various problems facilitates the understanding, the conceptual assimilation, and critical analysis, all of which contribute to student's success in finding a valid solution. In the present P's PBL, obtaining information by ubiquitous computing is creating demand of more debate and discussion in the classroom, thus necessitating active collaboration and teamwork. The mismatch between the evaluations of the accuracy, the adequacy of the information in the context in which it will be used and the contextualization of information between the reflective critical analyses of curriculum concepts is obvious. The P's PBL with ICT use and ubiquity of information is an instruction that appeals directly to students' interests. Thus, it increases their responsibility for their own learning progress and their professional future. Through explanation, inquiry, critical analysis and reformulation of relevant and complex problems, the students take more active role in the acquisition of necessary skills and the development of personal characteristics needed for success in the field of architecture and building construction.

\section{References}

Barrows, H. S. (1986). A taxonomy of problem-based learning methods. Handbook on Problem-Based Learning., 20(6), 481-486. https://doi.org/10.1111/j.1365-2923.1986.tb01386.x

Bouchlaghem, D., Shang, H., Whyte, J., \& Ganah, A. (2005). Visualisation in architecture, engineering and construction (AEC). Automation in Construction, 14(3), 287-295. https://doi.org/10.1016/j.autcon.2004.08.012

Crooks, G. E. (2009). Comment regarding "On the Crooks fluctuation theorem and the Jarzynski equality" [J. Chem. Phys. 129, 091101 (2008)] and "Nonequilibrium fluctuation-dissipation theorem of Brownian dynamics" [J. Chem. Phys. 129, 144113 (2008)]. The Journal of Chemical Physics, 130(10), 107101. https://doi.org/10.1063/1.3080751

Ferro, C., Martínez, A. I., \& Otero, M. C. (2009). Ventajas del uso de las TICs en el proceso de enseñanza aprendizaje desde la óptica de los docentes universitarios españoles. Revista Electrónica de Tecnología Educativa, 29, 1-12.

Fonseca, D., Martí, N., Redondo, E., Navarro, I., \& Sánchez, A. (2014). Relationship between student profile, tool use, participation, and academic performance with the use of Augmented Reality technology for visualized architecture models. Computers in Human Behavior, 31, 434-445. https://doi.org/10.1016/j.chb.2013.03.006

Fonseca, D., Redondo, E., Valls, F., \& Villagrasa, S. (2016). Technological adaptation of the student to the educational density of the course. A case study: 3D architectural visualization. Computers in Human Behavior, 1-13. https://doi.org/10.1016/j.chb.2016.05.048

Fonseca, Climent, Vicent, \& Canaleta. (2016). Learning4work. Designing a new evaluation system based on scenario centered curriculum methodology: The pre-test. Lecture Notes in Computer Science (including subseries Lecture Notes in Artificial Intelligence and Lecture Notes in Bioinformatics) (Vol. 9753). https://doi.org/10.1007/978-3-319-39483-1_1

Glick, S., Clevenger, C., \& Porter, D. (2011). Integrating 3D Models in Construction Management Education : Masonry Interactive Homework. In 47th ASC Annual International Conference Proceedings (pp. 261-265). Omaha, US.

Grife, J. N. Z., Carcaño, R. G. S., \& Fajardo, J. A. G. (2014). Design and development of software for optimal material cost estimating on aluminum works. Revista de La Construccion, 13(3), 45-53.

Kocaturk, T. (2010). A Web-Based Teaching/Learning Environment to Support Collaborative Knowledge Construction in Design. Journal of Information Technology in Construction, 15, 271-290.

Kondratova, I., \& Goldfarb, I. (2004). Knowledge portal as a new paradigm for scientific publishing and collaboration. ITcon, 9(11), 161-174.

Leopold, C., Gorska, R. a., \& Sorby, S. a. (2001). International Experiences in Developing the Spatial Visualization Abilities of Engineering Students. Journal for Geometry and Graphics, 5(1), 81-91.

Marchesi, Á. (2004). Da linguagem da deficiência às escolas inclusivas. In Desenvolvimento psicológico e educação (Second Edi, p. 720). Artmed Editora.

Martí, N., Olivé, J., Adroer, M., Aumedes, X., Belii, X., Espinàs, J., Gelpí, C., Mateu, N., Prat, X. \& Armand, P. (2014). Tecnologia - Construcció, Aula de Materials i Tallers in Situ. Retrieved from http://www.salleurl.edu/tecnologia/

Monereo Font, C. (2012). El aprendizaje estratégico: FAQ. Arbela: Hezkuntza Aldizkaria, 44, 50-56.

Nawari, N. O. (2010). Intelligent design in AEC education. Electronic Journal of Information Technology in Construction, 15, 306-317.

Prensky, M. (2004). The emerging online life of the digital native.

Torres-Machi, C., Chamorro, A., Yepes, V., \& Pellicer, E. (2014). Current models and practices of economic and environmental evaluation fo sustainable network-level pavement management. Revista de La Construcción, 13(2), 49-56. https://doi.org/10.4067/S0718915X2014000200006

Weiser, M. (1991). The Computer for the 21st Century. Scientific American, 265(3), 94-104. https://doi.org/10.1038/scientificamerican0991-94 